\title{
La lectura eclesial origeniana de la Escritura en el Comentario a Mateo
}

\author{
JUAN PABlo SEPÚlVEDA HERNAIZ* \\ Pontificia Universidad Católica de Chile (Chile) \\ jbsepulv@uc.cl
}

\begin{abstract}
Resumen
El artículo reflexiona sobre la estructura hermenéutica que subyace a la práctica interpretativa origeniana, tal y como se despliega en el Comentario a Mateo. Para conseguirlo, la reflexión se dispone en torno a tres aspectos de la interpretación: su finalidad, su ambiente vital y sus criterios de verificación. En su conjunto, la revisión de estos aspectos evidenciaría que la interpretación origeniana de la Escritura toma sus condiciones de sentido de las principales convicciones de la fe de la Iglesia, justificándose el adjetivo eclesial para la lectura origeniana. Tal ejercicio sistemático se pone en relación con una pregunta esencial para la hermenéutica bíblica contemporánea: ¿es posible leer la Escritura de manera crítica y confesional a la vez?
\end{abstract}

Palabras clave: Orígenes, lectura eclesial, Comentario a Mateo, hermenéutica bíblica.

\section{Origen's ecclesial reading of Scripture in the Commentary on Matthew}

\begin{abstract}
The article reflects on the hermeneutic structure that underlies the Origen's interpretative practice just like it unfolds in the Commentary on Matthew. To achieve this, the paper is organized with regard to three aspects of interpretation: its purpose, its vital environment and its verification criteria. As a whole, the review of these aspects would show that Origen's interpretation of Scripture takes its conditions of meaning from the main convictions of Church's faith, justifying the ecclesial adjective for the Origen's reading. Such systematic exercise is related to an essential question for contemporary biblical hermeneutics: is it possible to read Scripture critically and confessionally at the same time?
\end{abstract}

Key words: Origen, ecclesial reading, Commentary on the Gospel of Matthew, biblical hermeneutics.

\footnotetext{
* Magíster en Teología con mención en Teología Patrística. Profesor Instructor de la Planta Adjunta de la Facultad de Teología de la P. Universidad Católica de Chile. Jefe de Programa del Diplomado en Estudios de la Religión del Centro de Estudios de la Religión UC. Áreas de desarrollo: Teología Bíblica, Religión Popular en Chile. Otros artículos recientes del autor: "Los fiscales de Chiloé como ejemplo de efectivos agentes transmisores de la fe cristiana: criterios para pensar la evangelización en un contexto plural" (2019).

Esta investigación contó con apoyo pecuniario brindado por CONICYTPFCHA/MagísterNacional/2018 - 22180063.
} 


\section{INTRODUCCIÓN}

Los estudios sobre Orígenes y sus cuestiones exegéticas son abundantes $^{1}$, por lo que me parece que una cuestión clave es justificar la pertinencia de cada nueva publicación que se sume a tan rico - no solo en cuanto a su número, sino también en cuanto a su calidad científica- elenco. Por lo tanto, es preciso declarar que este trabajo no pretende sacar a la luz alguna nueva cuestión totalmente inadvertida o descuidada sobre la exégesis origeniana, sino que intenta ser una reflexión teológica en torno a una cuestión plenamente vigente y que se apoya en el doctor alejandrino como su fuente para la argumentación.

De lo que aquí se trata es de aportar en la discusión respecto de la hermenéutica en la interpretación bíblica: ¿existe una hermenéutica propiamente eclesial, es decir, que proponga un marco de referencia para una determinada comunidad de fe, a saber, la Iglesia Católica? Es evidente que nos encontramos con algunos elementos para responder a esta pregunta en la Constitución Dogmática Dei Verbum, pero ¿es posible leer la Escritura de manera crítica y confesional a la vez, tal como se propone en el número 12 de tal documento magisterial? ${ }^{2}$

Sin duda que es una cuestión que me supera desde todo punto de vista y que bajo ningún aspecto pretendo agotarla —es más, pienso que debe ser una pregunta siempre abierta - pero que, como teólogo, me desafía a ensayar una reflexión, simplemente porque toca un aspecto medular del quehacer teológico y que inevitablemente la resolvemos cada vez que hacemos teología, ya sea que tengamos o no algún grado de conciencia de nuestra respuesta.

Para esto, recurro a Orígenes, autor que ha sido determinante para la exégesis patrística ${ }^{3}$, y en cuyo trabajo interpretativo descubro elementos que considero esenciales para enfrentar la cuestión hermenéutica actual. Por otra parte, el Comentario a Mateo $(C M t)$, trabajo de la época más madura

1 Tan solo como ejemplo, se puede mencionar al artículo de Perrone (2015) referente a las publicaciones recientes sobre Orígenes, publicado en el número 21 de la revista Adamantius. Igualmente son destacables los trabajos de Piscitelli (2008) y las traducciónes de Heine (Orígenes, 2018a; 2018b).

2 Uno de los autores que más me ha motivado a una reflexión en esta dirección es Joseph Ratzinger, quien en varios escritos plantea (por ejemplo, 1983; 1985: 157-80; 2005a; 2005b), por una parte, la tensión que se produce entre una interpretación que sea crítica y confesional al mismo tiempo, y, por otra parte, la importancia de la exégesis patrística para iluminar esta cuestión.

Se trata de una apreciación que comparten importantes especialistas en relación con la exégesis origeniana (por ejemplo, de Lubac, 1950: 38-46; Nautin, 1977: 225-260; Dively, 2005: 1-2; Martens, 2012: 1-4). 
del Alejandrino ${ }^{4}$, me proporciona un material suficiente como para analizar las operaciones exegéticas que nuestro autor despliega.

Entonces, el presente artículo significa un esfuerzo sistemático por evidenciar la estructura — que denoto por medio del sintagma lectura eclesial- que sostiene y articula a la compleja práctica exegética origeniana tal como se presenta en el $C M t^{5}$. Cabe señalar que la tradición textual ha conservado 8 tomos en lengua griega (Mt 13,36-22,33), lo que representa una cantidad de material suficiente para los objetivos que me he propuesto. Consciente de que los estudios actuales muestran plausiblemente que el texto griego de tradición medieval es una de varias redacciones abreviadas de un original más amplio, lo mismo la versión latina, lo asumo sin más como el texto base, debido al alcance del presente estudio: aproximarse al pensamiento histórico del autor en relación con su práctica exegética. Asimismo, la edición de Klostermann (Orígenes, 1935) es actualmente criticada por las conjeturas que la subyacen y la contaminación que conllevó su decisión de confrontar la redacción griega con la latina, en su pretensión por acceder al sentido querido por Orígenes. Pese a esto, sigue siendo una edición de referencia para traducciones a lenguas modernas, como la de la editorial Città Nuova.

La tesis que intentaré mostrar es que tal estructura configura la práctica exegética origeniana determinando tres aspectos de su interpretación: su finalidad, su ambiente vital y sus criterios de verificación. Cada uno de estos tres aspectos será tratado en su propio acápite, pero, como se podrá apreciar, están internamente relacionados entre sí. Cierro el artículo con algunas reflexiones que retoman la cuestión inicial a la luz del itinerario cursado.

4 Compuesto entre 244 y 249 d.C. en Cesarea de Palestina, el CMt es un texto de síntesis en el que confluye lo mejor de la experiencia origeniana precedente: Orígenes se radica en esta ciudad portuaria por el 234 d.C. y la convierte en su residencia más estable hasta el final de su vida. En este período se ponen por escrito cientos de homilías y obras tan célebres como el Comentario al Cantar de los Cantares y el Contra Celso. Su residencia en la región enriquece su ejercicio exegético mediante la familiarización con la geografía bíblica, la disponibilidad de manuscritos y el contacto intelectual con la comunidad judía local, que le permite informarse de tradiciones y del pensamiento judío de aquel tiempo. Además, es un escrito que puede considerarse como un referente de su actividad escolástica (Danieli, 1998: 38-46).

5 Para el análisis de los extractos fundamentales incluidos en la argumentación del presente escrito, me baso en edición clásica de Klostermann (Orígenes, 1935 [GCS, X]). Además, para la lectura del conjunto y para la traducción al español de los extractos en griego me apoyo en la edición crítica de Città Nuova (Orígenes, 1998; 1999; 2001; 2015). 
Pareciera que la finalidad de la exégesis origeniana es propiciar una relación de intimidad con el Logos ${ }^{6}$ : para el Adamantino la Escritura efectivamente es palabra de Dios, pero, al mismo tiempo, se constata que existe una cierta distancia entre su significado inmediato y la verdad salvífica que le subyace. ${ }^{7}$ Por consiguiente, el principal objetivo que persigue la exégesis origeniana es intentar colmar tal distancia ${ }^{8}$, de forma que el exégeta se constituye en un verdadero agente catalizador de la comunicación entre Dios, que quiere manifestarse a sí mismo mediante la Escritura, y el ser humano, que responde a esta revelación por medio de su fe.

Sin duda que aquí nos sale al paso la cuestión del sentido espiritual de la Escritura, principio metodológico determinante para la praxis interpretativa origeniana y que ha sido ampliamente estudiado por varios autores?. Baste tan solo señalar que la distinción fundamental entre sentido literal y espiritual de la Escritura es mencionada varias veces por Orígenes en el Comentario a Mateo ${ }^{10}$, destacando la glosa que incorpora en CMt XVII,34 porque testimonia la insuficiencia del sentido literal, al que el Adamantino

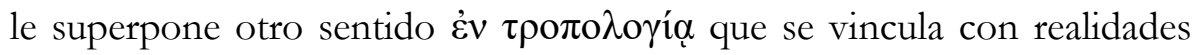
referidas a Cristo.

$6 \quad$ Se trata de una tesis que tomo prestada de K. Torjesen (1986), quien afirma que la interpretación cumple para el Adamantino una función mediadora cuyo fin es que el destinatario se encuentre con el Logos en la Escritura, mediante un proceso de purificación e instrucción que desemboca en la contemplación de Dios.

Orígenes enfrenta de manera más sistemática esta cuestión en Princ., IV,2,9-3,5: el sentido inmediato de la Escritura, por disposición del Espíritu, está llena de piedras de tropiezo - proporciona múltiples ejemplos de esto en Princ., IV,3,1-3,3- cuyo objeto es estimular al intérprete a buscar el propósito primordial de la Escritura, el que se vincularía con la salvación de los hombres y que se consigue mediante la articulación coherente de las realidades espirituales (Princ., IV,2,9).

8 Un aspecto clave en la tesis de Torjesen (1986) es la interpretación que hace de Princ., IV,2,4: al comentar Pr 22,20 Orígenes se estaría dirigiendo al maestro exégeta, quien tiene que considerar las diversas fases progresivas del alma en su camino dinámico hacia la salvación. Así, los tres niveles de lectura del texto se conectarían con tres niveles de enseñanza y, correlativamente, la Escritura contendría en sí un progresivo orden de doctrinas en correspondencia con los diferentes estados de crecimiento del creyente, que el exégeta debería ponerlos en operación para la comunidad de la que es parte. Bajo este enfoque, el principal factor estructurante de la exégesis origeniana sería el así llamado "viaje del alma", proceso pedagógico que consta de tres estadios que se relacionan con los tres niveles de actividad de la trinidad: purificación, conocimiento y perfección.

9 Remito tan solo a Simonetti (2004: 13-28), cuyas reflexiones sobre el tema me parece que se avienen con la realidad que se descubre en el estudio de la práctica exegética origeniana.

10 Por ejemplo, en CMt X,1.16.18; XI,5.14; XII,24; XIII,1; XV,28; XVI,4.6; XVII,21. 
Adicionalmente, para Orígenes la señalada distancia entre la letra y el sentido espiritual de la Escritura se relaciona con la pedagogía del Logos: una manifestación divina libre de toda ambigüedad no podría ser recibida por el ser humano, ya que requiere de un proceso ascendente ${ }^{11}$ que haga posible la asimilación de los misterios que se le revelan. Esto resulta totalmente coherente con aquella afirmación incluida en su tratado sobre la Escritura (Princ. IV,3,15) de que el propósito secundario del Espíritu es la estimulación del intelecto mediante "piedras de tropiezo" que inciten a la razón a ascender hacia las realidades eternas. De ahí que se deba considerar la idea de gradualidad en la misma interpretación, ya que no todos los creyentes están en condiciones de asimilar los misterios ocultos (reservados para los perfectos; CMt XII,37), siendo necesario para el exégeta también buscar aquellos sentidos que contribuyen al crecimiento espiritual (de los que están progresando; CMt XII,31) o incluso encontrando provecho en el sentido inmediato (útil para los simples; $C M t \mathrm{XII}, 30$ ).

Por otra parte, la insuficiencia del sentido literal deja espacio a la posibilidad del error, es decir, a una mala comprensión que distorsiona el diálogo, mediado por la Escritura, entre el Logos y el creyente. Por esta razón, la práctica interpretativa origeniana también destaca por incluir una dimensión polémica ${ }^{12}$ que combate a otras propuestas exegéticas que reducen, obstaculizan o francamente se oponen a la verdad salvífica oculta en el texto.

Un pasaje representativo de esta preocupación origeniana lo hallamos en la lectura tropológica que el Adamantino hace de la narración mateana sobre la transfiguración de Jesús frente a algunos de sus discípulos en el monte Tabor (Mt 17,1-9):

Dado que en seis días, cifra perfecta, fue creado todo el mundo, pienso que esta creación perfecta se manifiesta a quien sobrepasa toda realidad

11 Orígenes pareciera explotar el contraste entre la multitud y los discípulos (véase $C M t$ X,1.4.25; XI,1-7.18; XII,5.17.31; XIV,15; XVI,9.26; XVII,14), como recurso literario para destacar al discipulado como el itinerario paradigmático de todo creyente, el que está marcado por un progresivo conocimiento de las realidades ocultas del Logos. En efecto, el discípulo, en virtud de su modo propio de seguimiento del Logos $(C M t \mathrm{XV}, 8)$, es llevado a la "otra orilla" de las realidades espirituales (CMt XI,6) logrando así contemplar los misterios que subyacen a las acciones simbólicas de Jesús $(C M t$ XVI,26) con el objeto de llevar el "alimento espiritual" a la multitud hambrienta que sigue a Jesús (CMt XI,1).

12 Pareciera que las digresiones de tono polémico que se descubren en el CMt se dirigen al lector a modo de advertencias o peligros vinculados con interpretaciones que el Adamantino considera inadecuadas y que, por consiguiente, acogerlas implica un detrimento en el progreso espiritual. Pienso que pueden agruparse en torno a dos grandes ejes: el literalismo bíblico, cuyo pasaje emblemático se encuentra en $C M t \mathrm{XI}, 14$; y la lectura extra eclesial de la Escritura, desarrollada principalmente en CMt XII,12. 
terrenal al observar, no más las "cosas visibles" (porque estas son "pasajeras"), sino "las invisibles" y tan solo "las invisibles" (porque estas son “eternas"), seis días después Jesús toma consigo algunos de estos. Ciertamente si alguno de nosotros desea que Jesús lo tome consigo y lo lleve a un monte alto y lo considere digno de contemplar en privado su transfiguración, supere los seis días, no mediante la observación de "lo visible" ni el amor "al mundo ni a lo que está en el mundo", ni consciente en desear un deseo mundano, que es deseo de los cuerpos, ni de la riqueza para el cuerpo y la gloria según la carne, y abandone aquello que al alma separa y arrastra de lo mejor y divino y la rebaja e inclina al engaño de este siglo en la riqueza y la gloria y a los restantes deseos odiados por la verdad. Porque siempre que se supere los seis días (por así decirlo), celebrará un nuevo sábado, gozando en el monte alto de ver transfigurado a Jesús frente a él. Porque diferentes formas tiene el Logos, manifestándose a cada uno de manera adecuada al que ve y a ninguno por sobre su capacidad ${ }^{13}$.

Como se puede apreciar, este extracto deja en evidencia el interés de Orígenes por persuadir a su lector a buscar las realidades eternas — por medio del cese de los deseos hacia las engañosas realidades terrenas-, de manera que en éste se actualice el misterio de la transfiguración. Así, parece plausible la afirmación de que para Orígenes el ejercicio escolar de la interpretación de la Escritura no se disocia de su vocación o carisma eclesial, entendiendo su propia tarea exegética como la de un facilitador del ascenso espiritual del creyente para que a éste le sea posible un acceso más pleno al Logos.

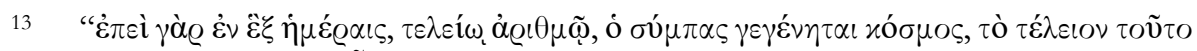

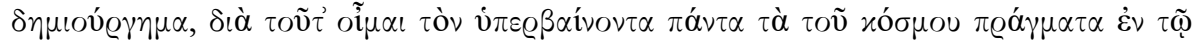

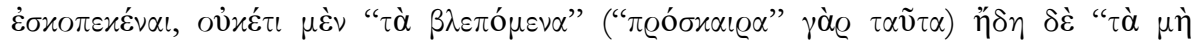

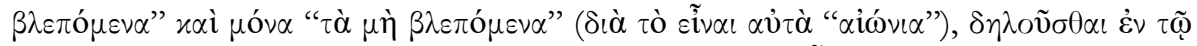

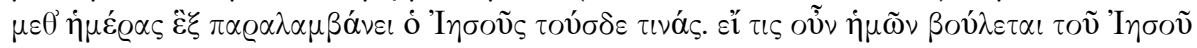

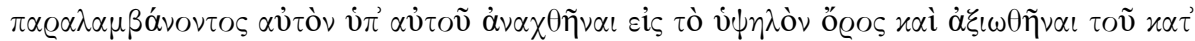

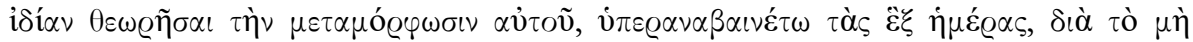

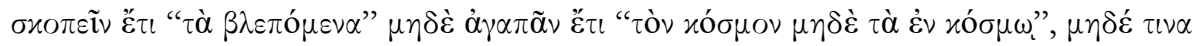

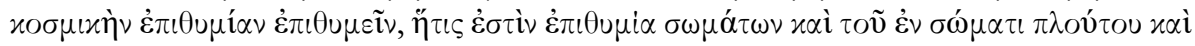

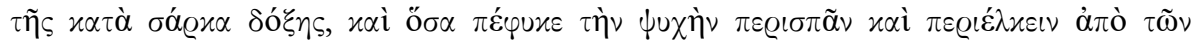

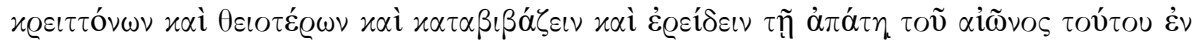

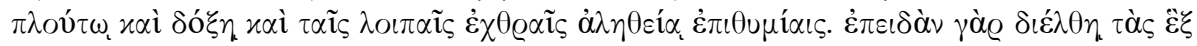

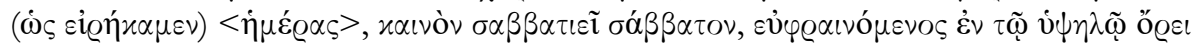

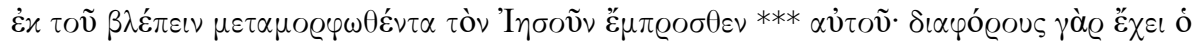

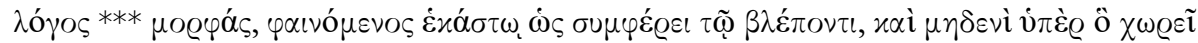

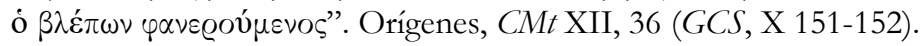




\section{LA IGLESIA, AMBIENTE VITAL DE LA INTERPRETACIÓN}

En segundo lugar, es manifiesto que para el Alejandrino la interpretación de la Escritura encuentra su ambiente propio en el seno de la comunidad de fe. Sin tener que recurrir a algún argumento técnico al modo del praescriptione haereticorum de Tertuliano, en el Comentario a Mateo encontramos tres aspectos que dan por sentado que la Iglesia, en virtud de su comunión con el Logos, es el genuino intérprete de la Escritura: la comunidad eclesial es el destinatario propio de la interpretación; el intérprete es tal gracias a su propio progreso espiritual; la jerarquía eclesial es garante de la interpretación.

Si bien la cuestión de la comunidad creyente como horizonte de la labor exegética de la Escritura ya fue tocada a propósito del fin de la interpretación, es oportuno añadir que es un asunto que se deja apreciar en las múltiples digresiones de tono polémico que se encuentran repartidas por todo el Comentario a Mateo. Estas inclusiones parecieran cumplir una función preventiva frente a doctrinas ajenas a la Iglesia, que debe ser fiel a la predicación apostólica, enseñanzas que son propiedad de comunidades heterodoxas fundadas en los engaños de Marción, Basílides y Valentín (CMt XII,12). No obstante, la cuestión no puede reducirse únicamente a las escuelas fundadas por los tres heresiarcas nombrados, sino que aparentemente estas tres escuelas funcionan como grupos paradigmáticos ${ }^{14} \mathrm{de}$ quienes interpretan de forma inadecuada porque no están unidos verdaderamente a Cristo y por ello no alcanzan el verdadero sentido de la Escritura (CMt X,15; XI,14; XV,3; XVII,13.18) convirtiéndose así en el blanco predilecto del Adamantino en las digresiones polémicas.

Por su parte, la atención a las condiciones morales y espirituales del intérprete como condición para acceder a los misterios que contiene la Escritura es un enfoque instalado recientemente por P. Martens (2012), quien pone el acento en el horizonte existencial del intérprete como la fuerza central y organizadora del proyecto exegético del Adamantino: para Orígenes, una adecuada idea de la Escritura dependería del proceso sostenido de formar buenos hábitos y compromisos interpretativos, por eso Martens intenta describir el perfil de lo que Orígenes concibió como el

\footnotetext{
14 Podría tratarse de un estilo de Orígenes, en el que sus "adversarios" cumplen una función retórica que busca persuadir al lector en una determinada dirección: "En tant qu'hérésie il a perdu sa singularité, son identité, il a été assimilé par la réflexion théologique comme l'envers de la vérité, il n'est plus qu'un élément du jeu parfaitement intégré à la problématique chrétienne. C'est à ce titre qu'il peut jouer le rôle de norme négative dans le Peri Archôn. Les signes de la déformation ne manquent pas dans l'ouvrage, à commencer par la reprise de la thèse des «natures» déterminées attribuée aux gnostiques, dont on remet en cause aujourd'hui la justesse" (Le Boulluec, 1975: 55).
} 
intérprete ideal: su formación escolar (filología y crítica literaria), su búsqueda religiosa y espiritual, su tarea — principalmente apologética — en la comunidad eclesial y el lugar que le corresponde en la economía de la salvación. El Comentario a Mateo no es suficiente como para desarrollar la tesis de Martens, pero sí nos ofrece unas llamativas digresiones en las que el Alejandrino parece estar orando en solicitud de la asistencia divina que le permita enfrentar con éxito su tarea interpretativa (CMt XV,27.31; XVI,20; XVII,6.32), pasajes que nos permiten, al menos, aproximarnos a esta dimensión históricamente desatendida de la exégesis origeniana.

Respecto a la función de la jerarquía eclesiástica como garante de fidelidad a la predicación apostólica, el Comentario a Mateo nos ofrece una interesante reflexión sobre la importancia que esta cuestión tiene para Orígenes:

En seguida, uno debe observar que se acercaron a él los discípulos, así como discípulos proponiendo problemas al maestro y examinando quién es el más grande en el reino de los cielos. Y al menos en estas cosas deben ser imitado los discípulos de Jesús. Si después alguno preguntando entre nosotros no encuentra respuesta, con total acuerdo acerca de la pregunta, acerquémonos a Jesús que está presente donde "dos o tres se reúnen" (Mt 18,20) en su nombre, y que es capaz, con su presencia según nuestra capacidad, de iluminar los corazones de quienes sinceramente quieren ponerse en su escuela para la comprensión de las preguntas. Pero no está mal también acercarse a alguno de los maestros ordenados por Dios en la Iglesia para proponerle un problema análogo: ¿quién es el más grande en el reino de los cielos?15

En el texto citado se advierte cómo el Adamantino elabora un discurso parenético que no solo invita a una actitud de curiosidad sino que también identifica a la comunidad creyente, habitada por el Logos, como el espacio propicio para llegar a la comprensión de los misterios cristianos: la sede que Jesús instituye como su cátedra es la propia Iglesia $(C M t \mathrm{XI}, 18)$ y por ello es posible afirmar que Cristo enseña exclusivamente al interior de ella, mientras que a los que están fuera de esta comunidad el Maestro

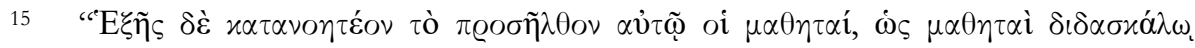

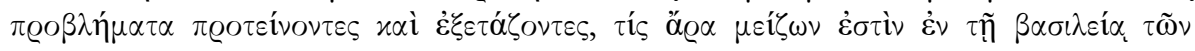

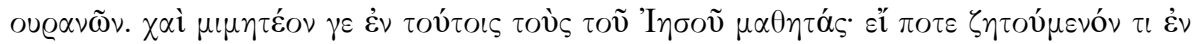

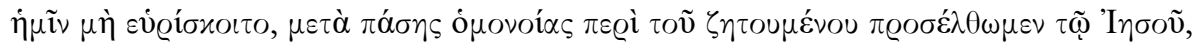

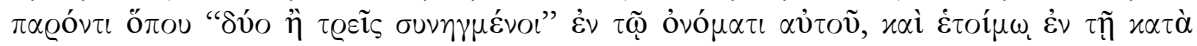

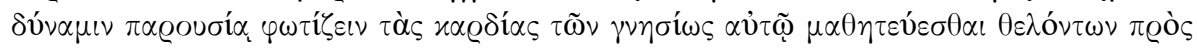

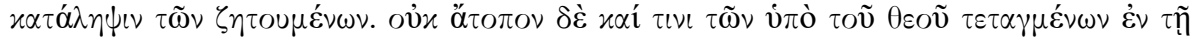

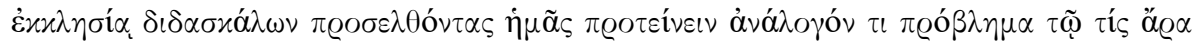

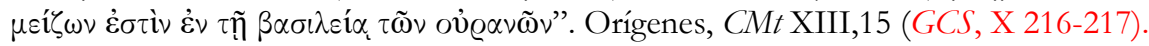


se dirige por medio de preguntas (CMt XVII,3). Además, se destaca el rol particular de aquellos miembros de la comunidad instituidos por Dios como doctores de la enseñanza apostólica. Me parece que aquí se aprecia en toda su magnitud la dicotomía que existe entre acceder directamente al Logos con el riesgo de subjetivismo que ello conlleva y recurrir a la asistencia de un doctor eclesiástico, capacitado para transmitir la doctrina apostólica normativa.

Para comprender mejor qué entiende Orígenes por los "maestros ordenados por Dios en la Iglesia"16, es útil atender a aquellos personajes que en su comentario realizan aquella función: los discípulos son los encargados de llevar el alimento espiritual a la multitud (CMt XI,1); son los que conocen los misterios del reino de los cielos y por eso mismo son los intermediarios entre el Logos y la multitud, congregación incapaz de tomar el alimento espiritual directamente de manos de Jesús (CMt XI,4); Jesús edifica sobre la confesión de fe de Pedro toda la enseñanza de la Iglesia ( $C M t$ $\mathrm{XII}, 10)$; los apóstoles reciben una enseñanza que no les es exclusiva sino que también es propia de todo quien la aprenda (CMt XII,16); la entrada mesiánica en Jerusalén (Mt 21,6-11) es un símbolo de que Jesús instituye su cátedra sobre los vestidos de los discípulos docentes (CMt XVI,18; XVI,15).

En consecuencia, es plausible pensar en una suerte de continuidad entre los discípulos y los mencionados maestros, por lo que resulta espontáneo pensar en la sucesión apostólica y, por extensión, en el orden sacerdotal. No obstante, no se debe perder de vista el contraste fundamental que se da entre los discípulos y la multitud, que junto a reflexiones respecto de que las promesas de Jesús hechas a los discípulos —incluso aquella dirigida a Pedro a propósito de su confesión de fe (CMt XII,11)—, en el comentario origeniano aparecen vinculadas a un mayor o menor grado de progreso espiritual y no a algún ministerio eclesial determinado. De esta manera, podría sospecharse que este grupo no se podría reducir a lo que hoy llamaríamos jerarquía eclesiástica ${ }^{17}$, sino que también puede incluir, por ejemplo, exégetas laicos, pero siempre asociados a un mandato que

\footnotetext{
16 Es importante señalar que, para Orígenes, tales maestros no tendrían asegurado el éxito de su ministerio docente solamente en virtud de su elección. Es una cuestión que se ilustra con aquellos maestros pertenecientes a la Iglesia que transmiten una enseñanza infructuosa y que son comparados con aquel hombre que, respetando la ley del levirato, toma como esposa a la mujer de su hermano, pero sin darle hijos (CMt XVII,32).

17 Cabe señalar que se trata de una labor que pareciera implicar la dedicación de la vida del intérprete. Un aporte importante para esta cuestión lo encuentro en la tesis de Martens (2012: 161-191), quien afirma que el intérprete ideal para Orígenes participa del drama cristiano de la salvación, lo que además involucra una determinada integridad y conducta moral.
} 
viene del propio Cristo dado a sus apóstoles y estos, a su vez, han prolongado por medio de sus sucesores oficiales.

En su conjunto, los tres aspectos desarrollados en el presente acápite (la interpretación de cara a la comunidad, el progreso espiritual del intérprete, y la vinculación con la predicación apostólica) dan cuenta de que la Iglesia, es decir, la comunidad que, animada por el Espíritu, se une a Cristo participando de su vida y su verdad, puede ser considerada como el legítimo intérprete de la Escritura, ya que, en virtud de su comunión con el Logos, es capaz de descubrir el sentido espiritual, el único sentido que hace del texto un mensaje tanto actual como salvífico.

\section{LOS CRITERIOS DE VERIFICACIÓN DE LA INTERPRETACIÓN}

La tercera dimensión que se ve determinada por la hermenéutica eclesial origeniana se vincula con los criterios de verificación que regulan su práctica exegética. En el Comentario a Mateo el criterio eclesial más evidente es la regla de fe, la que a su vez se inserta en un marco más amplio que es el de la tradición apostólica — en la que la sucesión apostólica, como vimos anteriormente, cumple un papel fundamental-, pero también destaca la razón como luz que guía al intérprete hacia las realidades eternas ocultas en la Escritura.

\subsection{La regla de fe}

Se debe advertir que la regla de fe opera al modo de un conjunto de presupuestos teológicos que influyen en la interpretación bíblica (Fernández, 2005). Los dos más determinantes para la hermenéutica origeniana son: la consideración de Cristo como la clave hermenéutica de la Escritura $^{18}$ y la unidad de toda ella en un conjunto armónico y coherente ${ }^{19}$.

Para el Adamantino la clave de interpretación de la Escritura es Cristo mismo, incluso llegando a postular la identificación entre él (Logos) y la

\footnotetext{
18 "Sin embargo, se debe decir que el carácter divino de las palabras proféticas y el carácter espiritual de la ley de Moisés brillaron [solo] cuando vino Jesús. Pues antes de la venida de Cristo, era casi imposible mostrar ejemplos claros de la inspiración divina de las antiguas Escrituras. [...] Y la luz que se contiene en la ley de Moisés, que ha sido encubierta por un velo, brilló con la venida de Jesús, pues fue quitado el velo y, en breve, se dieron a conocer los bienes de los cuales la letra contenía una sombra”. Orígenes, Princ., IV,1,6 (FuP 27, 815).

19 "Este Dios, justo y bueno, Padre de nuestro Señor Jesucristo, Él mismo dio la ley, los profetas y los evangelios, el cual es también el Dios de los apóstoles, así como del Nuevo y del Antiguo Testamento”. Orígenes, Princ., Pref.,4 (FuP 27, 121-123).
} 
Escritura $^{20}$. Es posible apreciar esta identificación en $C M t \mathrm{X}, 4-6$, donde el Alejandrino hace un interesante paralelismo entre Cristo y la Escritura cuando interpreta alegóricamente la parábola del tesoro escondido en el campo de Mt 13,44.

En consecuencia, Orígenes practica la lectura cristológica de la Escritura, moneda de cambio de la interpretación cristiana de la Escritura durante la patrística. Es un aspecto tan fundamental de su teoría exegética que su presencia en el Comentario a Mateo es generalizada y forma parte —más o menos explícitamente- de prácticamente toda interpretación particular presente en esta obra. No obstante, es posible señalar una sección en la que se ilustra vivamente esta convicción: la interpretación que nos ofrece al comentar la comparación jesuánica entre el reino de los cielos y el comerciante de perlas finas (Mt 13,45-46; CMt X,7-10). En su comentario, el Alejandrino introduce una analogía que es especialmente importante para la cuestión:

Pero, la líder del colectivo de las perlas, la que encontrada también se encuentran las otras, la perla de gran valor, es el Cristo de Dios, la Palabra por sobre los valiosos escritos, los pensamientos de la ley y los profetas, que habiendo sido encontrada también fácilmente son asumidas todas las demás realidades ${ }^{21}$.

Esta analogía relaciona a Cristo con los textos veterotestamentarios - representados con la expresión "la ley y los profetas"-, explicitando que Cristo es la clave hermenéutica del sentido espiritual del AT. Se trata de una convicción tan significativa para nuestro autor que recurrentemente vuelve a ella en el Comentario a Mateo: el AT encuentra su cumplimiento en los evangelios y en las palabras de Jesús transmitida en la tradición apostólica $(C M t \mathrm{X}, 12)$; con el rechazo de Jesús, el punto capital de la profecía, queda en evidencia que los judíos rechazan su propia tradición profética (CMt X,22); los profetas con sus sufrimientos prefiguraron la venida sin apariencia ni belleza del Salvador (CMt XII,30); con la economía de la encarnación se erige un templo de piedras vivas y se inaugura el ver-

20 "Egli non si limita a considerare la Scrittura come libro divinamente ispirato dallo Spirito santo, ma in quanto parola divina l'identifica effettivamente con Cristo $=$ Logos, parola di Dio (Cels. 6,77; Ser.Mt. 27): la Sacra Scrittura è la permanente incarnazione del Logos" (Simonetti, 1985: 78).

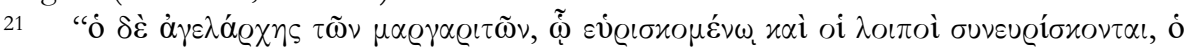

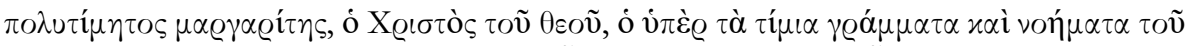

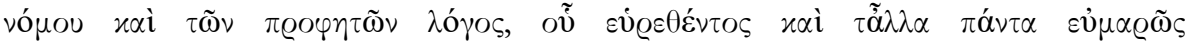
$\pi \alpha \varrho \alpha \lambda \alpha \mu \beta \alpha ́ v o v \tau \alpha \iota "$. Orígenes, CMt X,8 (GCS, X 9-10). 
dadero culto, en contraposición al culto y al templo judío que son pasajeros (CMt XVI,3); los ciegos de Jericó son símbolo de los judíos (en los dos reinos de Israel y Judá), y su incapacidad de ver al Logos verdadero en la ley y los profetas (CMt XVI,10); Cristo es la piedra en que se articulan los dos ángulos del AT y NT (CMt XVI,12).

En definitiva, Cristo es "líder del colectivo de las perlas" porque, llevando a cumplimiento la antigua alianza, revela que la encarnación es el punto culminante de la única economía de la salvación, y la entrega kenótica del Logos es la condición de posibilidad de que el alma racional pueda ser iniciada en el conocimiento de los misterios ocultos en virtud de su salvación. Así es posible afirmar que una vez "encontrada" tal perla, tendremos acceso a las realidades eternas contenidas en los textos de la Antigua Alianza.

Por su parte, la unidad de la Escritura ya queda insinuada con la lectura cristológica: hay un Logos, una economía, por consiguiente, una Sagrada Escritura. Dado que el $C M t$ no pretende ser un trabajo sistemático, esta doctrina también debe ser reconstruida a partir de múltiples comentarios y reflexiones dispersos en la obra, aunque es destacable el lugar privilegiado que la unidad de la Escritura ocupa en el método de interpretación origeniano, específicamente en su insistencia en iluminar a la escritura con la misma escritura. Un extracto en que vemos resaltado este presupuesto teológico lo encontramos en la enseñanza de Jesús sobre los dos o tres que en su nombre se reúnen para orar (Mt 18,19-20):

Es un gozo ejercitar, entender y dar razón de la armonía de los dos testamentos, aquel anterior a la venida en cuerpo del salvador y el nuevo: en efecto, allí donde los dos testamentos están en armonía, en el punto que no hay discordancia entre ellos mismos, se puede encontrar una plegaria tal que sobre cualquier cosa que pidan les será concedida por su padre del cielo.

Si también deseas poseer el tercero, el ensamblador de los dos, no dudo decir que éste es el Espíritu Santo [...] y no dejar inobservado lo que de hecho dijo: "donde dos o tres están reunidos allî" no estaré, sino "estoy". No es que esté por hacerlo, que tarde, sino que en cuanto se realiza la armonía, también él se encuentra en medio de ellos ${ }^{22}$.

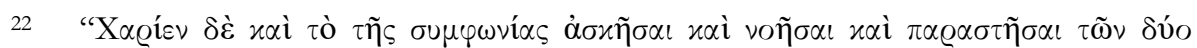

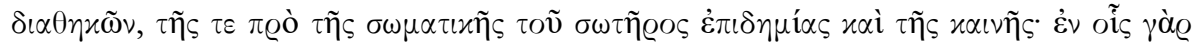

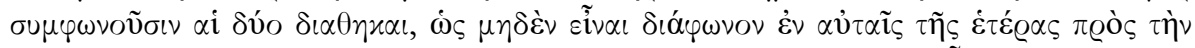

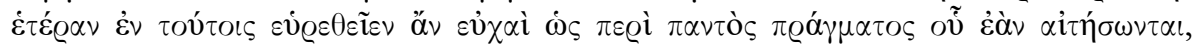

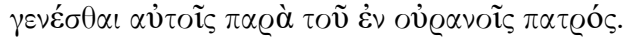

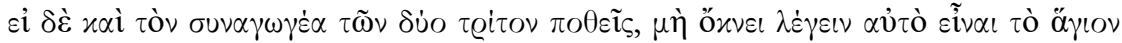

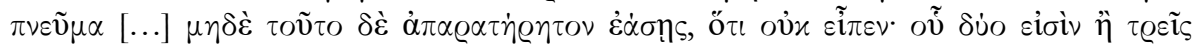


Tal como se puede apreciar, el teólogo alejandrino expresa el acuerdo

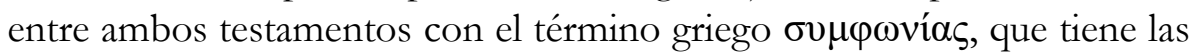
acepciones de armonía, concordia, unanimidad. Al mismo tiempo, se afirma que la mencionada armonía entre testamentos abre la posibilidad de elaborar una plegaria digna de ser atendida por el Padre. Además, como el relato de Mateo habla de dos o tres que están reunidos en el nombre de Jesús, Orígenes, sin vacilar, incluye al Espíritu como el tercer agente de la armonía y ensamblador de los otros dos. Asimismo, nuestro autor vincula todo lo anterior con la promesa jesuánica de hacerse inmediatamente presente en cuanto este acuerdo entre AT y NT se materialice.

Sin embargo, la cuestión a resolver es cómo puede darse el acuerdo entre textos que son tan disímiles entre sí en cuanto a su forma y contenido. Como vimos anteriormente, esta cuestión se juega en la habilidad del intérprete para encontrar el propósito primordial de la Escritura mediante la articulación coherente de las realidades espirituales (Princ., IV ,2,9). Esta exigencia de coherencia en el nivel espiritual es una condición que se extiende a toda la Escritura, incluido el Nuevo Testamento ${ }^{23}$. Por lo tanto, aquí nos encontramos con el fundamento teológico que explica que un recurso básico de la exégesis origeniana sea la confrontación con otros pasajes de ambos testamentos para iluminar el significado espiritual de un determinado pasaje ${ }^{24}$.

Ahora bien, esto mismo lo encontramos desplegado y efectivamente aplicado en todo el Comentario a Mateo, en las innumerables ocasiones en que el Adamantino intenta iluminar el sentido de un determinado relato

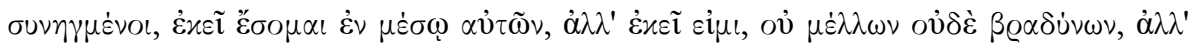

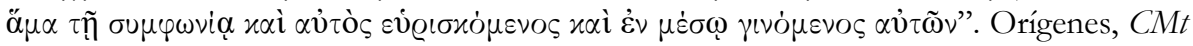
$\mathrm{XIV}, 4$ (GCS, X 280-281).

23 "Ahora bien, el Espíritu ha realizado esta disposición no solo respecto de los [escritos] anteriores a la venida [del Hijo], sino que, dado que es el mismo [Espíritu] y que proviene del único Dios, ha hecho lo mismo respecto de los evangelios y de los apóstoles, puesto que tampoco ellos articulan un relato histórico completamente simple de acuerdo a lo corporal, pues contienen hechos que no han ocurrido, y una legislación y unos preceptos que no ofrecen en ellos algo totalmente razonable". Orígenes, Princ., IV,2,9 (FuP 27, 867-869).

24 "Por esto, es necesario que con precisión el lector, observando el mandato dicho por el Salvador: Escrutad las Escrituras, investigue atentamente dónde el sentido literal es verdadero y dónde es imposible, y según su capacidad, a partir de los términos semejantes, siga la huella del sentido profundo — diseminado por toda la Escritura- de los [pasajes] que, de acuerdo a la letra, son imposibles. Pues bien, como será evidente a los lectores, mientras la coherencia es imposible en lo que se refiere a la letra, por el contrario, el [sentido] primordial no solo no es imposible, sino verdadero". Orígenes, Princ., IV,3,5 (FuP 27, 887-889). 
con otros pasajes escriturísticos, pero también en sus esfuerzos por interpretar manteniendo siempre la coherencia y el nexo lógico, no solo al interior del mismo evangelio, sino que también con la Escritura en su conjunto (CMt X,18; XII,14.22.34; XIII,17; XIV,10; XVI,16.18; XVII,29), e incluso resolviendo aparentes tensiones que se dan en el relato según la interpretación más inmediata (CMt X,16; XI,10; XIV,20; XVI,1).

Por último, hay que mencionar otras dos metáforas que complemen$\tan$ a la de la armonía respecto del principio de la unidad de la Escritura: la red que es echada al mar de Mt 13,47 que es aprovechada como imagen de las diversas partes de la Escritura, cuyos sentidos se entrelazan como una red que atrapa a quienes entran en ella $(C M t \mathrm{X}, 12)$; y la transfiguración de Jesús en el Monte Tabor, en el momento en que los discípulos levantan sus ojos y ven solo a su maestro, quien antes estaba en compañía de Moisés y Elías $(M t 17,1-9)$, escena que sugiere, al nivel de la realidad mística, que los profetas y la ley llegan a ser una sola realidad con el evangelio, y que el Logos encarnado es su principio articulador (CMt XII,43).

Entonces, el trasfondo que está a la base de la imagen de la armonía entre ambos testamentos es la convicción teológica de la unidad de la Escritura, principio interpretativo que determina la práctica exegética origeniana, ya que este acuerdo no se da en el nivel de interpretación más inmediato de los textos, sino que reclama del intérprete la búsqueda de la coherencia a nivel espiritual.

\subsection{La luz de la razón}

Orígenes no solo destacó por su interpretación espiritual, sino que también por elevar el nivel de la exégesis cristiana en el ámbito de la aproximación filológica ${ }^{25}$ que, por lo demás, se trata de una faceta coherente con la identificación entre la Escritura y Cristo: a la dimensión humana de

25 'L'altro carattere dell'esegesi origeniana su cui richiamo qui in apertura l'attenzione e che ha fatto fare all'esegesi cristiana un incalcolabile salto di qualità portandola ai livelli della più scaltrita esegesi greca e forse anche più avanti, è l'approccio filologico al testo biblico. Origene è consapevole dei contrasti che nascono, nelle discussioni con i giudei, per divergenze fra il testo biblico in uso rispettivamente presso l'uno e l'altro contendente; non gli sfugge neppure che gli gnostici a volte modificano il testo sacro per farlo quadrare meglio con le loro dottrine; soprattutto sente l'esigenza di fondare l'interpretazione della Scrittura, che è parola di Dio, su una ricerca preliminare tesa a fissare l'esattezza di tale parola. Da questa esigenza sono nati gli Hexapla, un'armonia del testo ebraico e delle traduzioni greche del VT, la cui utilizzazione da sola ha avuto l'effetto di rivoluzionare ab imis i caratteri dell'esegesi scritturistica cristiana. E anche nell'ambito del testo greco del NT Origene ha cura di mettere a confronto più esemplari per rilevarne le eventuali divergenze e discuterle" (Simonetti, 1985: 76-77). 
Cristo se correspondería la letra de los textos sagrados. En efecto, la operación consistente en determinar la recta lección del texto bíblico es un paso esencial de su interpretación y la roca sobre la cual nuestro autor puede construir firmemente el edificio de la interpretación espiritual, soslayando así el riesgo de arbitrariedad anejo a tal aproximación escriturística $^{26}$.

Un buen ejemplo de tal preocupación por la letra del texto sacro lo encontramos a propósito de la enigmática orden que Jesús da a sus discípulos de no predicarlo como mesías en Mt 16,20 (CMtXII,15-19). Orígenes lo considera un detalle tan relevante que para su interpretación no solo recurre a la comparación sinóptica —que en la obra en estudio se muestra como un recurso básico para el comentario del evangelio (CMt XI,5.16; XII,35; XIII,19; XV,10; XVI,1.3.5.12.16.20.29; XVII,4.26.29)— sino que también recurre a la crítica manuscrita por medio de la consideración de las variantes que tiene a disposición.

En efecto, Mateo escribió según algunos de los manuscritos: entonces ordenó a los discípulos que no digan que él es el cristo. En Marcos: "les impuso severamente" dice "que no hablen a nadie sobre él". En Lucas: "ordenando severamente" dice "no transmitir a nadie esto" - pero ¿qué era "esto"? Ciertamente esto que, según él, Pedro habiendo respondido (a la pregunta "¿quién dicen que soy?”) dijo: "el Cristo de Dios". En efecto, se debe saber que algunos de los manuscritos de Mateo tienen la expresión "impuso severamente". La pregunta me parece realmente seria, pero se debe buscar una respuesta de ella irrefutable ${ }^{27}$.

En el extracto citado se advierte, en toda su radicalidad, la atención que otorga Orígenes a la letra en su práctica exegética, ya que no solo expone la dificultad que plantea la letra del relato, sino que se da la tarea de establecer filológicamente su relevancia con el recurso a las variantes manuscritas, como paso previo y necesario para profundizar en el sentido espiritual.

26 La interpretación gnóstica también empleaba una aproximación alegórica, pero Orígenes la desaprueba, entre otras cosas, por no estar debidamente conectada con la letra del relato (Simonetti, 1985: 84-88).

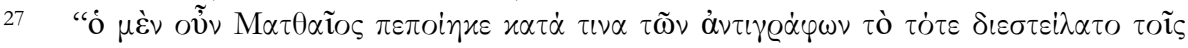

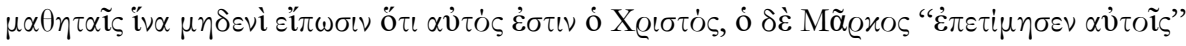

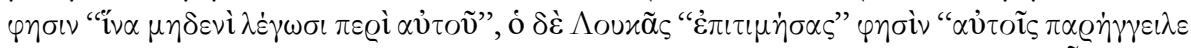
$\mu \eta \delta \varepsilon v i ̀ \lambda$ غ่

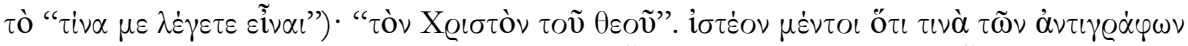

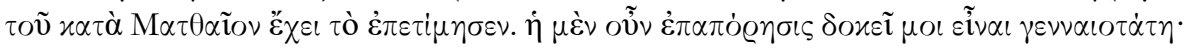
$\lambda \dot{u} \sigma \iota \varsigma \delta \grave{\varepsilon} \alpha \dot{v} \tau \tilde{\eta}_{\varsigma} \dot{\alpha} \nu \alpha \nu \tau i \varrho \varrho \eta \tau \varsigma \zeta \eta \tau \eta \theta \dot{\eta} \tau \omega ”$. Orígenes, CMt XII,15 (GCS, X 103). 
Además, es posible constatar que el Alejandrino recurría a una variedad de recursos lexicográficos ${ }^{28}$ para determinar el sentido preciso de la letra de la Escritura: a la ya mencionada determinación del sentido de un término o expresión mediante otros pasajes ${ }^{29}$, habría que agregar la profundización del sentido mediante el significado esotérico, tanto de las cifras (CMt XI,2-3; XII,36; XIV,5) como de los nombres propios (CMt $\mathrm{XI}, 6.16)$, y también la discusión sobre el sentido preciso con el que se emplean algunos términos en el texto sagrado (CMt XI,17; XII,34; XIII,23; XVII,7).

Finalmente, también se puede observar el rol relevante que tiene la razón en la interpretación origeniana cuando llega el momento de especular sobre cuestiones que no están definidas por la regla de $\mathrm{fe}^{30}$. La doctrina de la preexistencia de las almas puede servir para ilustrar esta cuestión, ya que es sugerida explícitamente por Orígenes en el Comentario a Mateo: la lectura espiritual de Mt 20,1-16 descubre en los obreros de la parábola un símbolo de las almas que el Logos llama a participar en la economía de la salvación. Sin embargo, los detalles literarios de la existencia de un lugar fuera de la viña - la plaza - sumado a el hecho de que algunos obreros estuvieran esperando allí durante la jornada, llevan a Orígenes a sospechar que en el texto se oculta una doctrina secreta sobre el alma humana ${ }^{31}$.

Entonces, debido a la convicción metodológica de que los detalles presentes en el relato tienen importancia para determinar el sentido del texto y por esto deben ser asumidos por la interpretación ${ }^{32}$, y el pie forzado de tener que dar cuenta de estos detalles del relato de forma coherente con la explicación que se viene desarrollando, la preexistencia de las almas -

28 Práctica que dista mucho de la imagen del alegorista acrítico con que en ocasiones se ha identificado a Orígenes, siendo Hanson un célebre representante de esta opinión: en su estudio sobre la exégesis origeniana (1959: 359-374), este autor termina por preguntarse sobre la diferencia entre el Adamantino y los grandes intérpretes de la talla de Agustín o Lutero, a lo que responde que estos grandes dan la impresión de hablar desde dentro de la Biblia, mientras que Orígenes vertería en la mente de los autores bíblicos sus propios pensamientos.

29 Ejemplos de su aplicación en la obra de estudio se encuentran en CMt X,13; XI,9.11.19; XII,34; XIII,19.23; XIV,13.16; XV,28-29; XVI,14.16.

30 El contenido de la regla de fe conocida por Orígenes lo encontramos en Princ., Pref.,4-8, junto con la advertencia de que la transmisión apostólica no fue igualmente clara en todos los puntos, quedando así algunas cuestiones para la investigación de parte de los miembros más talentosos de la comunidad. Entre estas cuestiones se encuentra la doctrina sobre el origen del alma humana.

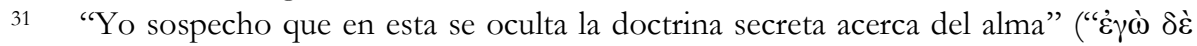

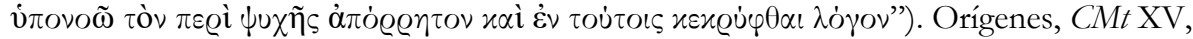
34 (GCS, X 451). La doctrina sobre la preexistencia de las almas Orígenes la desarrolla esencialmente en $C M t \mathrm{XV}, 35$.

32 Véase, por ejemplo, CMt X,13; XI,17.19; XIV,13; XV,29; XVI,12.14; XVII,6. 
doctrina de cuño platónico que eventualmente nuestro autor aclimata al ambiente cristiano a partir de la síntesis filoniana entre platonismo y judaísmo alejandrino (Bostock, 1987)— resulta útil para Orígenes en su afán por incorporar todos los detalles del relato en un conjunto coherente.

De modo que habría en Mt 20,1-16 un indicio que, puesto en el contexto de la tradición medio platónica, conduce a nuestro autor a proponer la preexistencia de las almas como una doctrina que podría acomodarse al sistema cristiano de mediados del siglo III ${ }^{33}$. De esta manera, se advierte que Orígenes se vale, sin prejuicios, de la tradición cultural alejandrina para profundizar el contenido de su fe y, al mismo tiempo, las verdades de la razón constituyen un criterio importante en su praxis exegética para colmar la insuficiencia de los datos proporcionados por la regla de la fe (CMt XIII,15).

Entonces, se puede afirmar que en la exégesis origeniana actúan diversos criterios de verificación que dialogan en el ejercicio interpretativo y que posibilitan que el texto esté siempre abierto a nuevas actualizaciones, es decir, para el Adamantino la interpretación de la Escritura es siempre una tarea por realizar y cada resultado debe ser considerado provisorio, sujeto de mejoras y complementos: "Y estas son las preguntas formuladas por nosotros en este lugar y las luces que dimos. Pero si hubiera alguien capaz de entender y decir las cosas mejor que nosotros, escúchenlo a él en lugar de a nosotros" ${ }^{\prime 3}$.

\section{REFLEXIONES CONCLUSIVAS}

En suma, se observa que a la interpretación origeniana le subyace una hermenéutica que podría caracterizarse como eclesial, porque se trata de una lectura que toma sus condiciones de sentido de las principales convicciones de la fe de la Iglesia: el Dios Trino que, mediante la encarnación kenótica del Hijo, manifiesta su palabra definitiva al ser humano en el marco de la única economía de salvación, asumiendo las limitaciones y equívocos que pudieran derivarse de su entrada en la historia y, a la vez, estimulando a las capacidades del ser humano para que éste no cese en la búsqueda del Logos.

\footnotetext{
33 Cabe señalar que se trata de una doctrina que se propone - al menos en esta obracomo solución provisoria, al modo de especulación, y no como una verdad de fe $(C M t$ $\mathrm{XV}, 35)$.

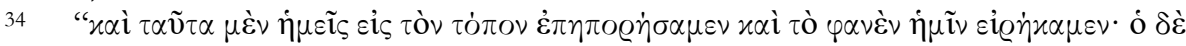

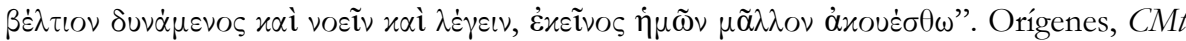
XVII,12 (GCS, X 618-619). Véase, CMt XI,7.18.19; XIII,4; XIV,5.7.12.14.22.24; XV,20.24.31; XV,5.17.19.
} 
En efecto, me parece que al sumergirse en su praxis exegética se encuentran algunas claves para pensar una interpretación de la Escritura que sea crítica y confesional a la vez, a la luz de lo planteado por el número 12 de la Dei Verbum, ya que ambas dimensiones no solo son constitutivas de su trabajo interpretativo, sino que están esencialmente ligadas.

Ciertamente, el contacto con el ejercicio interpretativo de Orígenes en una obra del género "comentario"- permite descubrir que ambas dimensiones conducen al intérprete hacia un diálogo creativo con el texto, sin por ello traicionar a la tradición religiosa a la que pertenece. Podría quedar la impresión de que sus convicciones de fe prevalecen sobre la gimnasia intelectual, pero nunca al extremo de cegar a la razón, sino que aquella actúa sobre esta iluminándola y orientándola hacia la verdad. Esta última cuestión es importante destacar porque se constata que no hay solución de continuidad entre fe y razón en la exégesis del Alejandrino; recordemos que en el sistema origeniano la Verdad se identifica con el Logos (Princ., Pref.,1), por lo que todo ejercicio racional tiene al Logos como su objeto más propio, por ello no es admisible una contradicción entre la regla de fe y los resultados que se obtienen al aplicar al texto bíblico las herramientas exegéticas alejandrinas.

Entonces, ¿cómo entra en diálogo esta propuesta con la exégesis contemporánea? Pienso que es ejemplar la honestidad intelectual del Adamantino al declarar cuáles son sus principios teológicos — principalmente en su obra De Principiis, pero también encontramos algunos de ellos dispersos en el Comentario a Mateo-y, al mismo tiempo, la rigurosidad con la que emplea los recursos intelectuales que adopta para estudiar el texto, aunque ello resulte incómodo para sus compromisos teológicos ${ }^{35}$. Tal vez, existen mejores herramientas exegéticas en la actualidad, metodológicamente hablando, y siempre es necesario ir evaluando los criterios que se emplean al momento de valorar los resultados, pero la hermenéutica eclesial que se descubre en su trabajo exegético levanta cuestiones estimulantes para la interpretación bíblica contemporánea: ¿es legítimo apelar a un principio estructurador, una regla hermenéutica para alcanzar una recta interpretación sin con ello renunciar a las exigencias críticas propias del siglo XXI? Para no dejar tan solo enunciada esta cuestión, remito a las reflexiones de K. Rahner (2007: 427-436) sobre la Escritura en tanto que libro de la Iglesia: se da una tensión entre la revelación trascendental y la histórica, pro-

35 Un ejemplo elocuente sobre esta cuestión es $C M t$ XII,15, que, como vimos, resulta difícil de interpretar sin caer en el absurdo, pero que Orígenes, a causa de su rigurosidad filológica, no puede pasar por alto la evidencia textual, que en la obra estudiada es incluso establecida con recurso a la crítica manuscrita. 
ceso en el que la Biblia se constituye como mediadora entre ambas realidades. Y dado que en la Escritura se objetiva la Iglesia del principio, es legítimo considerarla como una magnitud normativa a la vez que es signo del acercamiento definitivo de Dios al mundo. Por consiguiente, al plantear la cuestión de su inerrancia —a la luz del proceso de conformación del canon y también de la enseñanza sobre la inspiración- Rahner considera que aquella revelación de la que la Escritura es mediación se vincula propiamente con su totalidad y unidad, más que con sus elementos particulares. Esto justificaría explicitar un principio hermenéutico para su lectura que considere poner en relación las afirmaciones particulares con el conjunto de la fe, de manera de mantenerse fiel a aquella magnitud normativa de la que la Biblia es testigo.

Por otra parte, la exégesis origeniana pone de relieve la dimensión mística de la interpretación de la Escritura. Efectivamente, hay una determinada actitud que se espera del exégeta para llevar a cabo su servicio a la comunidad, una determinada manera de relacionarse con el Logos por medio de la interpretación, que se ilustra en términos de una relación discípulo-maestro. No obstante, es evidente que un texto es pasivo en relación con su lector, entonces ¿cómo puede darse tal relación de encuentro con el Logos? Las querellas contra el literalismo y contra la interpretación fuera de la Iglesia que encontramos sembradas en la obra nos llevan justo al centro de esta cuestión, ya que destacan que para Orígenes el cristianismo no es una religión del libro, en el sentido fuerte de la expresión, sino que nuestro autor entiende que las fuentes de la revelación son tanto la predicación apostólica como la Escritura, pero esta última leída en conexión vital con la comunidad animada por el Espíritu, conditio sine qua non para que el Logos enseñe hoy sobre las realidades referidas a Dios y a la salvación del ser humano. Insisto, ni el libro se basta a sí mismo (literalismo), ni la metodología exegética por sí sola (falsa gnosis) podría alcanzar la palabra que el Logos dirige a su Iglesia por medio de la Escritura.

En consecuencia, me parece admisible afirmar que la interpretación de la Escritura contribuye, en primer lugar, al progreso espiritual del propio intérprete que, en el ejercicio de su carisma exegético, entra en una privilegiada relación de intimidad con el $\operatorname{Logos}^{36}$. Se trata de una dimensión de la interpretación bíblica que aparentemente no ha sido lo suficientemente reflexionada en la exégesis contemporánea, pero que es determinante para situarnos frente a la pregunta inicial: si respondemos desde la práctica exegética origeniana, la contraposición entre crítico y confesional sería

36 Afirmación coherente con el incuestionable dato biográfico que habla del inquebrantable celo que Orígenes puso en el estudio de la Escritura, celo del cual el sobrenombre Adamantino da testimonio. 
un falso problema, ya que se trataría de dos vectores que en último término conducen al exégeta al objetivo más importante que tiene la interpretación, hacia un encuentro cada vez más pleno con el Logos.

\section{REFERENCIAS}

Bostock, G. (1987) The Sources of Origen's Doctrine of Pre-Existence. En L. LIES (ed.), Origeniana quarta: Die referate des 4. Internationalen Origeneskongresses (Innsbruck, 2-6 September 1985) (pp. 259-264). Innsbruck: Tyrolia.

Danieli, M. I. (1998). Introdurione. En Orígenes, Commento al vangelo di Matteo (R. Scognamiglio, Trad., Vol. I, pp. 5-46). Roma: Città Nuova.

de Lubac, H. (1950). Histoire et esprit: l'intelligence de l'Ecriture d'après Origène. Paris: Aubier.

Dively, E. A. (2005). The Soul and Spirit of Scripture within Origen's Exegesis. Boston: Brill Academic Publishers.

Fernández, S. (2005). Regulæ fidei et rationis: Tradición, razón y Escritura en los primeros siglos. Teología y Vida, 45(1-2), 103-121.

Hanson, R. P. C. (1959). Allegory and Event: A study of the Sources and Significance of Origen's Interpretation of Scripture. Virginia: John Knox.

Le Boulluec, A. (1975). La place de la polémique antignostique dans le Peri Archôn. En H. Crouzel, G. Lomiento \& J. Rius-Camps (Eds.), Origeniana: Premier colloque international des études origéniennes (Montserrat, 18-21 septembre 1973) (pp. 47-61). Bari: Universitá di Bari, Istituto di Letteratura Cristiana Antica.

Martens, P. (2012). Origen and Scripture: the Contours of the Exegetical Life. Oxford: Oxford University Press.

Nautin, P. (1977). Origène: Sa vie et son oewvre. Paris: Beauchesne.

Orígenes. (1935). Origenes Matthaüserklärung: die Griechisch Erbaltenen. (E. Klostermann, Trad.). Leipzig: J. C. Hinrichs'sche Buchhandlung.

Orígenes. (1998). Commento al vangelo di Matteo. (R. Scognamiglio, Trad., Vol. I), Roma: Città Nuova.

Orígenes. (1999). Commento al vangelo di Matteo. (R. Scognamiglio, Trad., Vol. II), Roma: Città Nuova.

Orígenes. (2001). Commento al vangelo di Matteo. (R. Scognamiglio, Trad., Vol. III), Roma: Città Nuova.

Orígenes. (2015). Sobre los principios. (S. Fernández, Trad.). Madrid: Ciudad Nueva. Orígenes. (2018a). The commentary of Origen on the Gospel of St Matthew. (R. Heine, Trad., Vol. I). Oxford-New York: Oxford University Press.

Orígenes. (2018b). The commentary of Origen on the Gospel of St Matthew. (R. Heine, Trad., Vol. II). Oxford-New York: Oxford University Press.

Perrone, L. (2015). Pubblicazioni recenti su Origene e la tradizione alessandrina. Adamantius, (21), 425-494.

Piscitelli, T. (Ed.) (2008). Il Commento a Matteo di Origene: atti del X Convegno di studi del Gruppo italiano di ricerca su Origene e la tradizione alessandrina, Napoli, 24-26 settembre 2008. Supplementi Adamantius, 2. Brescia: Morcelliana. 
Rahner, K. (2007). Curso fundamental sobre la fe: introducción al concepto de cristianismo (Segunda edición; R. Gabás, Trad.). Barcelona: Herder.

Ratzinger, J. (1983). Transmisión de la fe y fuentes de la fe. Scripta Theologica, 15(1), 9-29.

Ratzinger, J. (1985). Teoría de los principios teológicos: materiales para una teología fundamental. (M. Villanueva, Trad.). Barcelona: Herder.

Ratzinger, J. (2005a). La interpretación bíblica en conflicto: Sobre el problema de los fundamentos y la orientación de la exégesis hoy. En L. A. Sánchez Navarro \& C. Granados (Eds.), Escritura e interpretación: los fundamentos de la interpretación bíblica (Segunda edición; pp. 19-54). Madrid: Palabra.

Ratzinger, J. (2005b). La relación entre magisterio de la Iglesia y Exégesis. En L. A. Sánchez Navarro \& C. Granados (Eds.), Escritura e interpretación: los fundamentos de la interpretación bíblica (Segunda edición; pp. 175-187). Madrid: Palabra.

Simonetti, M. (1985). Lettera e/ o allegoria: Un contributo alla storia dell'esegesi patrística. Roma: Institutum Patristicum Augustinianum.

Simonetti, M. (2004). Origene esegeta e la sua tradizione. Brescia: Morcelliana.

Torjesen, K. (1986). Hermeneutical Procedure and Theological Structure in Origen's Exegesis. Berlin: De Gruyter. 